\title{
TACCA STARCH: A REVIEW OF ITS PRODUCTION, PHYSICOCHEMICAL PROPERTIES, MODIFICATION AND INDUSTRIAL USES
}

\section{Omojola $\mathrm{MO}^{* 1}$}

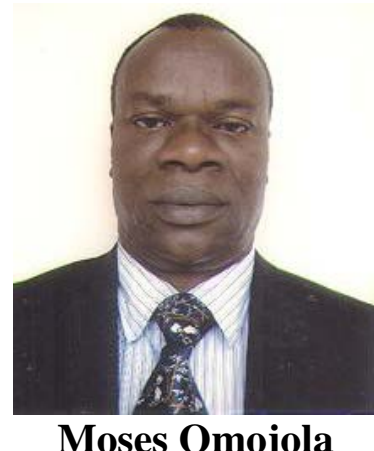

Moses Omojola

*Corresponding author email: omojolamoses@hotmail.com

${ }^{1}$ Raw Materials Research and Development Council, P.M.B. 232 Garki, Abuja. Nigeria 


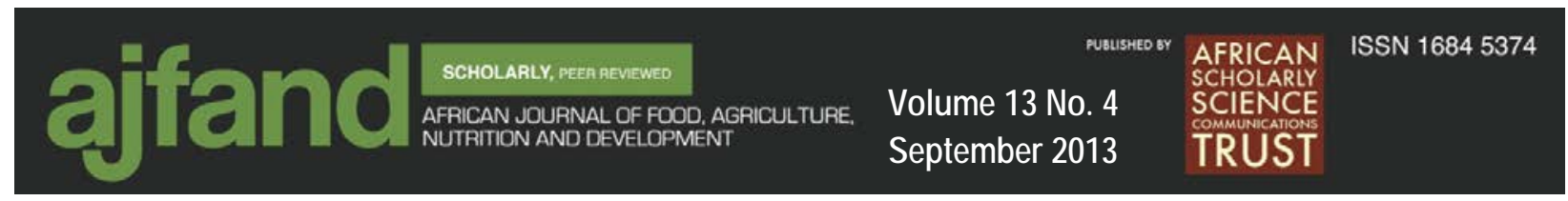

\begin{abstract}
The quest for cheaper and higher quality starch from biological materials has necessitated research into lesser known plants which have better physicochemical properties over the present commercial starch sources such as corn, cassava, potato, wheat and rice. Corn starch contributes about $80 \%$ of the total global starch production, which is dominated by the developed countries, whereas cassava production where the developing nations have comparative advantage contributes only $7.5 \%$, because cassava products are heavily consumed as staple food. A viable option is to develop some of the unutilized starchy crops that grow wildly in the developing countries. One of such plants is the generic Tacca, which is native to tropical regions of the world where it grows in the wild and domesticated in some areas of the Pacific islands. In Nigeria alone, these plants grow in the wild as in other parts of Africa, virtually unutilized with an annual production estimated at over 20 million MT. The extracted starch (over $30 \% \mathrm{wt} / \mathrm{wt}$ basis) and the modified derivative (citrate) have been found to be better disintegrants in drug formulations than corn starch, because of higher swelling power, and amylose content, almost zero fat and lower gelatinization temperature. It could also be used in the textile industry for stiffening fabrics. The African region does not have advantage in corn production because of high production cost arising from high requirements of fertilizer and pesticides coupled with severe drought. Investment in Tacca plantation and its industrial starch production can complement the cassava initiative revolution that is presently going on in Africa as a sustainable strategy to alleviate hunger and improve the economic growth of the continent. If the industrial potentials of Tacca plant are fully exploited for its starch production, it could make Africa significantly contribute to the global starch production. The available data on the industrial potentials of the plant and starch is adequate to encourage the domestication and cultivation of this tropical plant in African countries.
\end{abstract}

Key words: Tacca starch, physicochemical properties, utilization 


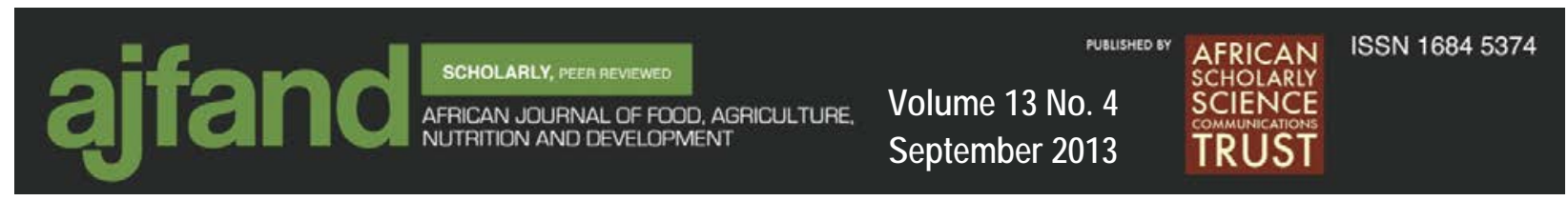

\section{INTRODUCTION}

Starch is one of the most versatile biomaterials in the food, textile, cosmetics, plastics, adhesives, paper and pharmaceutical industries. It is a renewable and almost unlimited resource material. About $54 \%$ of the starches produced globally are utilized for food applications with $46 \%$ for non-food applications. The diverse industrial usage of starch is premised on its availability at low cost, high caloric value, inherent excellence physicochemical properties and the ease of its modification to other derivatives. The industrial utilization of starch is determined by starch morphology and its physicochemical characteristics which are typical of its biological origin [1].

The present sources of commercial starch are corn (maize), wheat, potato, cassava and rice. Corn is the major source globally. In 2009, the world starch production was 68 million MT and projected to be 72 million MT in 2015 [2]. The global share of corn starch accounts for more than $80 \%$, whereas cassava starch is only $7.5 \%$ [3].

Corn (Maize) is a grain domesticated by the indigenous peoples in Mesoamerica in prehistoric times and now widely cultivated for its edible seed especially in tropical and warm temperate zones of the world. The present annual production exceeds over 1 billion MT with USA and China as the major producers. The major challenge in corn production is the high requirement of fertilizers and pesticides and high production costs could be very unbearable for peasant farmers in Africa and other developing nations of the world. Nevertheless, it has the advantage of long storage time without deterioration.

Cassava, also called tapioca, manioc or yucca in other parts of the world is one of the most important food crops in the humid tropics, being particularly suited to conditions of low nutrient availability and ability to survive drought [4]. It ranks very high among the crops that convert the greatest amount of solar energy into soluble carbohydrates per unit area. With over 200 million MT of world cassava root production, cassava starch contributes less than $8 \%$ of the world starch production compared to starches derived from most other plants. This is in spite of its greater paste clarity, viscosity, freeze-thaw stability and its high stability in acidic products [5]. It also has excellent properties for use in non-food production such as pharmaceuticals and thermo bio-plastics. In addition, its processing technique is simpler and cost of production lower than corn starch in particular. However, on a weight per weight basis, cassava yields a low quantity of starch $24 \%$, although in most varieties it can be as high as $32 \%$, compared to corn that yields about $65 \%$ starch. However, the high moisture content and other unfavourable storage conditions cause cassava starch losses, which mean that the root must be processed within 2-3 days. In the tropics, the agronomic performance of cassava has been developed over the years and improved varieties now mature at 12 months and yields range between 10-25 tons/ha [6]. The use of cassava for starch production faces stiff competition in many African countries where it is used to produce many staple products that yield more income to the farmers. Nigeria for example, is the highest producer of cassava 


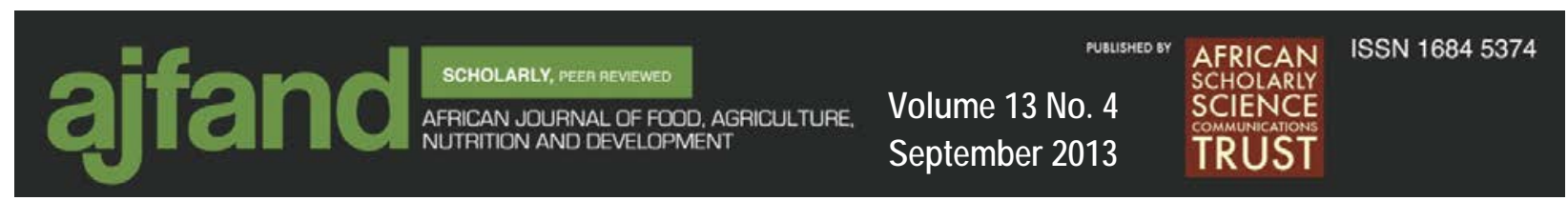

with over 40 million MT /annum, yet it contributes less than $2 \%$ of the global cassava starch production [6]. It, therefore, means that if Africa must compete in the global starch production, newer sources must be exploited among the carbohydrate crops that are not fully utilized as staple food materials, one of such plants is the generic plant Tacca. It consists of species such as Tacca involucrata (Schumach \& Thonn, 1827) and synonyms as: Tacca leontopetaloids (L.) Kuntze, 1891, Tacca hawaiiensis $H$. Limpr., 1928, Tacca cristata Jack, 1821 [7], order Dioscoreales and family Dioscoreaceae which in older texts was treated in its own family Taccaceae. The common names are Polynesian arrowroot and Bat flower. They are native to tropical regions of Africa, Australia, and South-eastern Asia, and have been domesticated in the Pacific island nations. The underground tubers are relatively hard and potato-like. The tuber serves as an important food source for many Pacific island cultures, especially amongst the inhabitants of low Islands [8]. It used to be a major source of carbohydrate in the savannah belt of Nigeria [9]. Each plant can produce 6-10 tubers weighing from 70 to $340 \mathrm{~g}$, but can reach $1 \mathrm{~kg}$ [10]. It has a maturity period of 4-5 months [11]. In Nigeria these plants grow in the wild, with an annual production estimated at over 20 million MT [6]. The proximate composition of the fresh tuber of Tacca was $1.10-1.50 \%$ protein, $2.70-2.73 \%$ ash, $0.28-0.68 \%$ fibre, $0.08-0.10 \%$ fat and 95.02-95.42 \% total carbohydrate on dry matter basis [8]. Tacca involucrate tubers yielded $30.23 \%$ starch on dry weight basis [12]. These values can be compared with some values on the composition of some starchy materials presently utilized as the commercial sources of starch $[8,12,13]$ as shown in Tables 1 and 2.

Tacca has lower fat and fibre contents compared to the other materials. The protein content is far lower than that of corn and comparable with that of potato and tapioca. On a dry basis, the starch contents of corn and wheat are higher than Tacca, whereas that of potato and tapioca are lower.

A review of the physicochemical and functional properties of Tacca starch and its derivatives as would be seen in this paper reveals that it can compare favourably with corn and cassava starches thereby freeing cassava tubers to produce staple foods that will alleviate hunger in many African countries especially in Nigeria and tubers like Tacca, can be maximally utilized for the industrial starch production. The production techniques for cassava and Tacca starches are comparable and very simple with low production costs.

\section{Starch isolation}

Starch is isolated by wet extraction process in unit operations. These operations include: washing, peeling, grating, screening, settling, dewatering, drying and pulverizing $[8,9,12]$ which are comparable with other tuber materials and quite different from cereals like corn. In cereals, the operations include: cleaning, steeping, milling and fraction separation, drying and pulverizing [14]. 


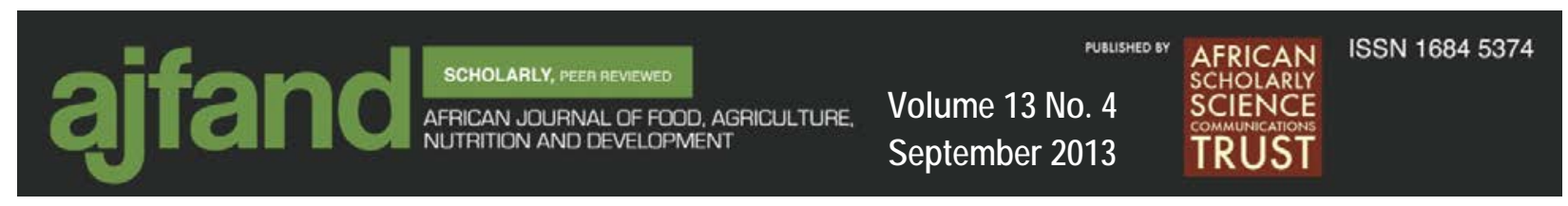

A comparative analysis of the production costs for starch isolation from tuber and cereal reveals that it is far cheaper to extract starch from tuber because it involves fewer unit operations which invariably reduce the energy cost.

\section{Tacca starch morphology}

The photomicrograph of Tacca starch extracted from Tacca involucrata in Fig. 1 shows that the starch granules are generally small sized and oval in shape with slight spacing between each unit of granule[15]. Another researcher reported that tacca starch granules from Tacca leontopetaloides were small (average particle size $3.5 \mu \mathrm{m}$ ) relative to maize and potato starches and were predominantly polyhedral with edges [16]. Nwokocha et al. [9] studied two species of Tacca- White and Yellow and reported that the granular size of white Tacca ranged from 6.13 to $18.12 \mu \mathrm{m}$ with average size of $12.32 \mu \mathrm{m}$ while yellow starch granules ranged from 4.19 to $11.98 \mu \mathrm{m}$ with granule average of $6.89 \mu \mathrm{m}$. This, clearly, shows that Tacca starch granules are smaller than potato starch $(5-100 \mu \mathrm{m})$ and other rhizome starches like cocoyam, tapioca and canna. It is also smaller than wheat and corn starches. Starch granule size affects gelatinization temperature and retro-gradation. Small sized granules result in low swelling power and high gelatinization temperature. Like corn starch, tacca starch demonstrates A-type crystallinity with the degree of crystallinity estimated at $38 \%$ and $35 \%$ respectively for the starches. This low crystalline order suggests probably high amylose content [17]. Generally, small and medium sized starch granules have been reported to have varied industrial utilization in the food and pharmaceutical industries for example tapioca, wheat, potato and cocoyam [18], and as such Tacca starch would be expected to have good industrial potentials. In addition, the small particle size along with a monomodal distribution and high amylose content indicate that tacca starch like cassava starch could be useful for fabric stiffening in the textile industry [17].

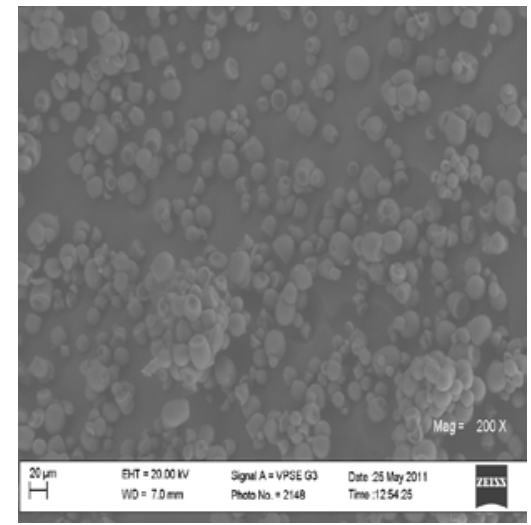

200X

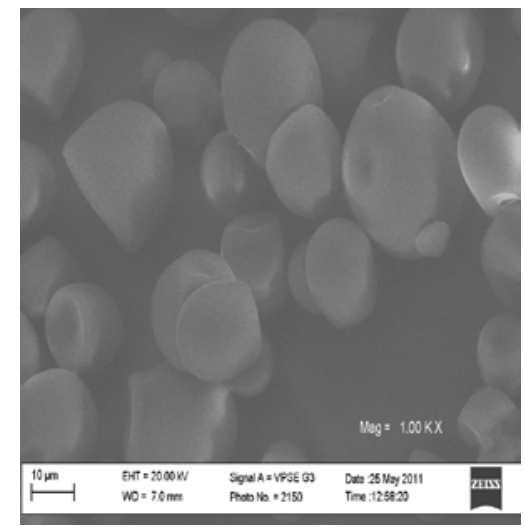

$1 \mathrm{KX}$

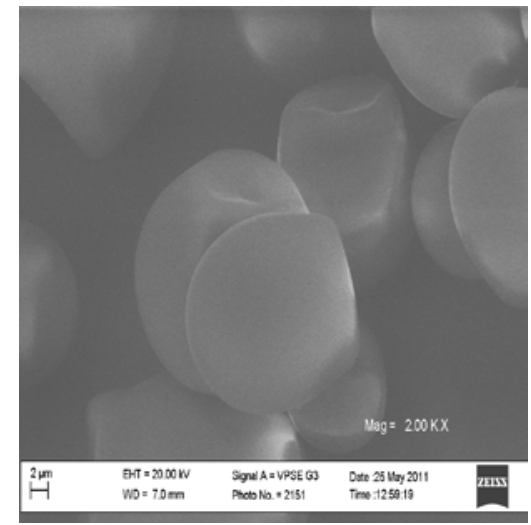

$2 \mathrm{KX}$

Figure 1: The photomicrograph of Tacca starch

\section{Physicochemical properties of tacca starch}

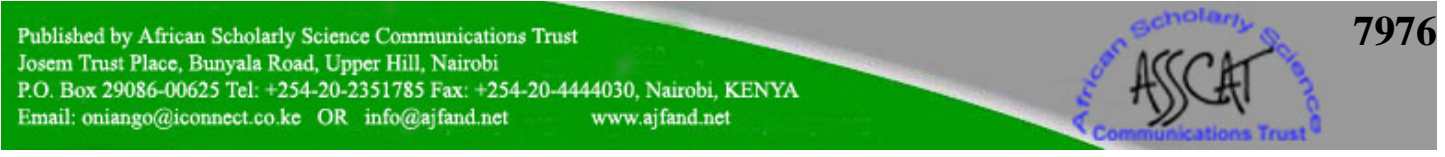




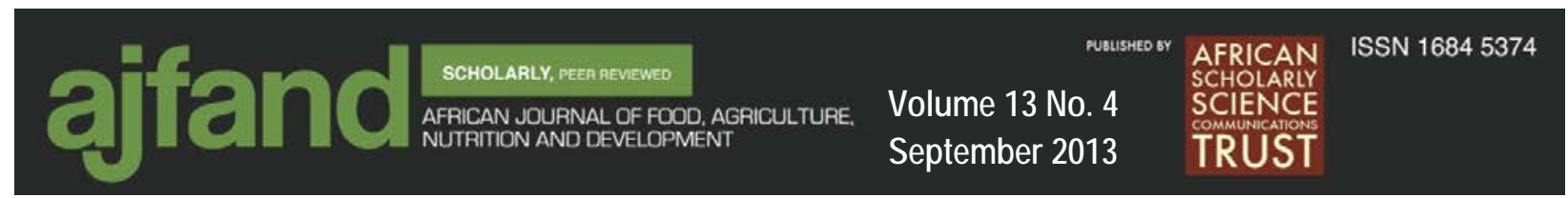

A number of researchers $[8,9,16]$, have studied the physicochemical properties of tacca starch. Tables 3 \& 4 are reproduced from Zaku et al.[12].

The typical parameters: moisture 9.15-10.00 \%, pH 5.2-5.8, protein 0.39-0.44 \%, bulk density $0.71-0.88 \mathrm{~g} / \mathrm{cm}^{3}$, amylose $28 \%$ and gelatinization temperature $62{ }^{\circ} \mathrm{C}$. It has almost zero fat and fiber contents. These values are in the same range to those of cassava starch [19]. The amylose content is above the normal range of 15-25 \% [20]. It is higher than that of cassava starch $17 \%$, while it is similar to that of corn starch 24-26\%. This also reflected in the low swelling power of tacca starch. The high amylose content also corresponds to a lower crystalline order of the spherulites [17]. The high content of amylose may suggest possible use in the manufacture of noodles [21]. The almost zero fat and fibre contents would make tacca starch unsuitable as an emulsifier in the food industry [22].

\section{SWELLING AND GELATINIZATION PROPERTIES}

The sequence of changes that occur when starch granules in the presence of water and heat form a paste is known as starch gelatinization. The temperature range where this process occurs is an important parameter in determining starch utilization in the industries. This parameter reflects the physicochemical properties of the starch which is a function of the botanical origin of the material. Gelatinization changes the viscosity of starch mixture, causing it to thicken. It also improves the availability of starch for amylase hydrolysis which is an important step in the breakdown of the starch to form different products [7].

Gelatinization is influenced principally by the starch particle size and the amylose/amylopectin ratio with larger starch granules absorbing water and swelling first. The temperature or amount of heat energy required for swelling or gelatinization of larger starch granules is lower. The more amylose a starch contains the higher the gelatinization temperature. This is because amylose molecules as a result of their linearity line up more readily and have more extensive hydrogen bonding and consequently it requires more energy to break these bonds and gelatinize the starch [23]. Starches with high amylose content also make a stronger, firmer gel because the linear amylose can move out of the granule into the water to easily align with one another and associate through hydrogen bonding. The freed amylose thickens and stabilizes the water around it and thus making the mixture thick and viscous. The amylopectin fraction on the other hand due to its branched structure has limited ability for hydrogen bonding and its solutions remain relatively clear and fluid [24].

Different gelatinization temperature has been reported for tacca starch. Adebiyi et al. [15] reported $62{ }^{\circ} \mathrm{C}$. Manek et al. [17] reported $68.56{ }^{\circ} \mathrm{C}$. Nwokocha et al. [9] reported $76.2^{\circ} \mathrm{C}$ for yellow tacca and $80.1{ }^{\circ} \mathrm{C}$ for white tacca. There is indeed a wide variation in these reported values such that it cannot be reported with certainty whether tacca's gelatinization temperature is lower than that of corn starch of $70-74{ }^{\circ} \mathrm{C}$ or that of cassava of $75{ }^{\circ} \mathrm{C}$. It has however been established that high amylose starch sometime 


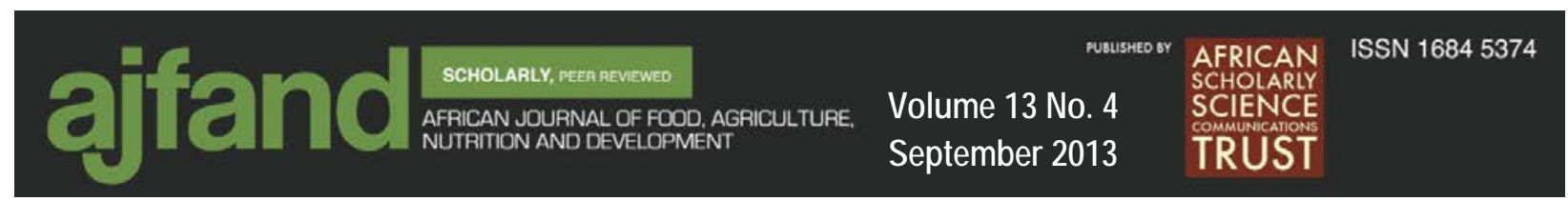

have high gelatinization temperature and since tacca starch has higher amylose content than corn and cassava starches, it may then be assumed that tacca starch would have higher gelatinization temperature than corn starch. Although, amylose content is not the only factor determining gelatinization temperature, agronomic practices and environmental factors contribute generally to physicochemical properties of starch.

Pure starches gelatinize faster, for example pure corn starch gelatinized at $17.6 \mathrm{~min}$ compared to $12.8 \mathrm{~min}$ for tacca starch. Longer gelatinization time is taken as evidence of the presence of other components other than starch. This further confirms the high purity of tacca starch.

Zaku et al. [12] reported a swelling power of $3.4 \mathrm{~g} / 10 \mathrm{ml}$, which is high when compared with other starches. Adebiyi et al. [15] found that the swelling capacity of tacca starch increases with increase in temperature. Kunle et al. [16] also reported that tacca starch had relatively higher swelling and solubility than other starches. This agreed with Nwokocha et al. [9] study, that yellow tacca starch with smaller granules exhibited higher swelling power and amylose leaching than white tacca starch. Increased swelling power is indicative of the suitability of such starch for use as a disintegrant in the pharmaceutical industry. The results therefore indicate that tacca starch would be a good disintegrant.

\section{VISCOSITY AND PASTING PROPERTIES}

Starch viscosity is largely influenced by the granule shape and swelling power, amylopectin-amylose entanglement and amylose/amylopectin interactions [25]. Waxy starches (high amylopectin contents) give high viscosity because amylopectin molecules do not align as easily and thus give weaker hydrogen bonding. High amylose starches give low viscosity. Starch viscosity changes with temperature, it is low in cold water, but upon heating, a thick paste with increased viscosity is formed. High viscosity is an indication of good quality native starch while low viscosity implies that the starch has undergone some degree of degradation during processing [26]. The high gelatinization starches have high pasting temperatures than the low gelatinization starches. These high pasting temperatures are attributed in part to the high amylose contents.

Paste clarity and freeze-thaw stability are important parameters in determining the stability of starch in many food processing. Nwokocha et al. [9] studied the effect of starch concentration on paste clarity and found that yellow tacca had slightly higher clarity than white tacca. The starches had minimum clarity at starch concentration of $1.5 \%$ with light transmittance increasing as starch concentration increased. The high paste clarity at higher starch concentration indicates that tacca starch would be suitable for the manufacture of food products where clarity is desired. 
The viscosity-shear rate profiles for $4 \%$ and $6 \%(\mathrm{w} / \mathrm{v})$ pastes of tacca starch showed a viscosity plateau $\left(\eta_{\mathrm{o}}\right)$ at lower shear rates and a shear thinning region at higher shear rates. The viscosity of the starch pastes was concentration dependant with $\eta_{\mathrm{o}}$ at $6 \%$ higher than $\eta_{\mathrm{o}}$ at $4 \%$. The effect of cold storage on the retro-gradation properties of tacca starch was also studied by [9] who observed that after 6 freeze-thaw cycles; the percentage syneresis was 36.72 for white tacca and 29.09 for yellow tacca. This indicates retro-gradation was more in white tacca than yellow tacca starch.

\section{Starch Modification}

From literature, tacca starch has been physically and chemically modified. Ofoefule et al. [27], carried out physical (pre-gelatinization) and chemical (acid hydrolysis) modifications on involucrata starch. The disintegrant and dissolution properties were investigated in lactose based tablets containing $0.001 \% \mathrm{w} / \mathrm{w}$ of riboflavin as tracer substance, $10 \% \mathrm{w} / \mathrm{w}$ tacca starch as disintegrant, $3 \% \mathrm{w} / \mathrm{w}$ acacia as binder, $1 \% \mathrm{w} / \mathrm{w}$ stearic acid as lubricant and enough quantity of lactose as diluents. It was concluded that pre-gelatinized tacca starch was more effective as a disintegrant than the acid hydrolysed form of the starch.

Attama et al. [28], also studied the effects of hypochlorite-oxidation on the physicochemical properties of starch obtained from tacca involucrate and observed that the oxidation produces starch of whiter colour and optically clearer mucilage. The process caused depolymerization, thereby yielding lower viscosity grades of starch with lower molecular weights. It also produces starch with smaller grain particles which had slightly poorer flow. It was concluded that oxidized tacca starch has limited use as a pharmaceutical excipient.

Adebiyi et al. [15], prepared tacca starch citrate derivatives to further improve its swelling properties and make it a better disintegrant in tablet formulations. The water absorption capacity, browning and charring temperatures of the modified starch were found to be higher than that of the native tacca starch. The citrate derivative had a higher swelling capacity than the unmodified starch at lower temperatures of 50-70 ${ }^{\circ} \mathrm{C}$. Since increase in swelling power is indicative of suitability of a starch being used as a disintegrant in the pharmaceutical industry, tacca starch citrate might be a better disintegrant in the formulation of tablets, than the tacca native starch.

\section{INDUSTRIAL USES}

The researches carried out on native tacca starch and tacca citrate starch as indicated in the above review show that both starches are better disintegrant in drug formulation than corn starch because of its higher swelling power, amylose content and moderate gelatinization temperature. The physicochemical properties of tacca starch also indicated that it could be suitable in processed foods like pies and puddings.

\section{CONCLUSION}


From the works of Nwokocha et al. [9], the flow characteristics and mechanical properties of the yellow and white tacca starch paste did not differ greatly. The tuber of some tacca species contains taccalin based bitter flavanoid content, which is undesirable, hence phytochemical analyses need to be carried out on the extracted starch to examine for the presence of this flavanoid and other phytochemicals [8]. Despite this further work, the available data on the industrial potentials of tacca starch should encourage governments in tropical countries to embark on the domestication and cultivation of this plant. 
Table 1: Composition of starch of raw material dry substance

\begin{tabular}{|l|c|c|c|c|l|}
\hline & Potato & $\begin{array}{c}\text { corn } \\
\text { (maize) }\end{array}$ & Wheat & Tapioca & Tacca \\
\hline Starch (\%) & 85 & 80 & 78 & 90 & 85 \\
\hline Protein (\%) & 3 & 5 & 8 & 1 & 1.5 \\
\hline Lipids (\%) & - & 2 & 1 & 1.5 & 0.1 \\
\hline Fibre (\%) & 4 & 1 & 2 & 2 & 0.7 \\
\hline
\end{tabular}

Table 2: Composition of starch raw materials as is

\begin{tabular}{|l|c|c|c|c|l|}
\hline Starch (\%) & 18 & 65 & 65 & 27 & 30 \\
\hline Protein (\%) & $<1$ & 6 & 7 & $<1$ & 0.3 \\
\hline Lipids (\%) & - & 2 & 1 & - & 0.1 \\
\hline Fibre (\%) & $<1$ & 2 & 2 & $<2$ & $<1$ \\
\hline Moisture (\%) & 80 & 18 & 15 & 75 & 9.2 \\
\hline
\end{tabular}

Table 3: Proximate compositions of the starch (on dry weight basis)

\begin{tabular}{ll} 
Parameter & Composition \\
\hline Starch yield (\%) & $30.23 \pm 0.01$ \\
Moisture (\%) & $9.15 \pm 0.02$ \\
Ash (\%) & $0.20 \pm 0.04$ \\
Crude protein (\%) & $0.31 \pm 0.02$ \\
Crude fiber (\%) & $2.10 \pm 0.06$ \\
Total lipids (\%) & $0.09 \pm 0.01$ \\
Carbohydrate (\%) & $88.07 \pm 0.00$ \\
Phosphate (ppm) & $98.80 \pm 0.23$ \\
Aqueous pH & $5.80 \pm 0.03$ \\
--------------------
\end{tabular}

The results are means of triplicate determinations \pm standard deviation. 
Table 4: Selected physicochemical properties of the starch

\begin{tabular}{|c|c|}
\hline Parameter & Composition \\
\hline Bulk density (g/cm3) & $0.81+0.33$ \\
\hline Amylase content (\%) & $28.07 \pm 0.04$ \\
\hline Swelling power (g/10m) & $0.4 \pm 00 \overline{1}$ \\
\hline Solubility power $(\%)$ & $66 . \overline{3}+0.02$ \\
\hline Water-binding capacity (\%) & $56 \pm 0.01$ \\
\hline
\end{tabular}

The results are means of triplicate determinations \pm standard deviation. 


\section{REFERENCES}

1. Gebre-Mariam T and PC Schmidt Isolation and physicochemical properties of Endset starch. Starch/Starke. (1996); 48(6):208-214.

2. Xiaohui Wang China corn processing industrial situation and outlook. Starch and ethanol. 2007.(accessed 22.06.2012). Available from http://www.agfdt.de/loads/st07/wang.pdf

3. Patil SK and Associates Strategic review of corn starch industry and markets-starch, sweeteners, bioprocessing and co-products. 2012 (accessed 22.08.2012).Available from http:// www.market research.com

4. Nyerhovwo John Tonukari Cassava and the future of starch. Electronic J. of Biotech. 2004; 7 (1) (accessed on 22.06.2012).Available from http://www.ejbiotechnology.info/index.php

5. Integrated cassava Project: Cassava starch production.2012 (accessed 22.06.2012). Available from www.cassavabiz.org/postharvest/starch03.htm

6. Raw Materials Research and Dev. Council ( RMRDC). Survey report on Agro raw materials, 2010.pg 10-11.

7. Germplasm Resources Information Network 2012 (accessed 07.11.2012) .Available from www.ars-grin.gov/cgi-bin/npgs/html/splist.pl?11828.

8. Ukpabi UJ, Ukenye $\mathbf{E}$ and AO Olojede Raw materials potentials of Nigerian wild Polynesian arrowroot (Tacca leontopetaloides) tubers and starch .J. of Food Technology. 2009; 7(4):135-138.

9. Louis MN, Chandra S and PA William Structural, physicochemical and rheological characterization of Tacca involucrate starch. Carbohydrate Polymers. 2011; 86: 789-796.

10. Root crops: East Indian arrowroot (Tacca leontopetaloides) 2012 (accessed 23.08.2012).Available from www.greenstone.com

11. Ahemen $\mathbf{S}$ and AO Raji Development and Performance Evaluation of a Motorized Rasping Machine for Tacca Involucrata Starch Production. J. Agric. Engr and Tech. 2008; 16(1):52-63.

12. Zaku SG, Aguzue OC, Thomas SA and JT Barminas Studies on the functional properties and the nutritive values of amura plant starch (Tacca involucrate) a wild tropical plant. African J. of Food Science. 2009; 3(10):320322. 
13. International starch institute 2012 (accessed 25.09.2012).Available from http:// www.starch.dk

14. Wang Shunsheng Report of the technical workshop on Corn \& starch deep processing technology held at Jilin Province light Industry Design \& Res. Inst. Changchun, China. Oct. $20^{\text {th }}-18^{\text {th }}$ Nov. 2003:17-117.

15. Adebiyi Adedayo B, Omojola Moses O, Orishadipe Abayomi T, Afolayan, Michael $\mathbf{O}$ and Olalekan Deborah Tacca starch citrate- A potential pharmaceutical excipient. Archives of Applied Science Research. 2011; 3(6):114-121.

16. Kunle OO, Ibrahim YE, Emeje MO, Shaba S and Y Kunle Extraction, Physicochemical and Compaction properties of tacca starch- a potential pharmaceutical excipient. Starch. 2003; 55 : 319-325.

17. Rahul V Manek, Olobayo O Kunle, Martins O Emeje, Philip Builders, Goparaju V Rama Rao, Gabriel P Lopez and William M Kolling Physical, Thermal and Sorption Profile of Starch Obtained from Tacca leotopetaloides. Starch. 2005; 57: 55-61.

18. Watson SA Starch: Chemistry and Technology. In $2^{\text {nd }}$ ed, Academic Press, New York. 1984. 461-462.

19. Sriroth K, Sautisopasri V, Patchalanuwat C, Kurotjanawong K, Piyachomkwan K and CG Oates Cassava starch granule structure - function properties: Influence of time and conditions at harvest in four cultivars of cassava starch. Carbohydrate Polymers.1999; 38: 161-170.

20. Ahmed AS, Igbo UE and CC Igwe Evaluation of the physics chemical properties of acid, thinned cassava starch. Nigerian Food Journal (2005);23: 85-90.

21. Shimelis E, Meaza $\mathbf{M}$ and S Rakshit Physicochemical properties, pasting behaviour and functional characteristics of flours and starches from improved bean (Phascohus Valgaris L.) varieties grown in East Africa. Agric Engr. Int. The CIGR e- Journal (2006) FP 05015 Vol. VIII.

22. Omojola MO, Akinkunmi YO, Olufunsho KO, Egharevba HO and EO Martins Isolation and physicochemical characterization of cola starch. African Journal of Food Agric Nutrition \& Dev. 2010; 10 (7):2884 - 2900.

23. Scot Hegenbart Understanding starch functionality.2012 (accessed 04.09.2012).Available from www.foodproduct.design.com/

24. Starch chemistry (2011).(accessed on 28.08.2012).Available from www.entertainment.howstuffworks.com 
25. Albert L Charles, Yung H Chang, Wen C KO, Klanaroth Sriroth, and Tzou C Huang Influence of amylopectin structure and amylose content on the gelling properties of five cultivars of cassava starches. J. Agric. Food Chem. 2005; 53 : 2717-2725.

26. Dzogbefia VP, Ofora GA and JH Oldham Physicochemical and pasting properties of cassava starch extracted with the aid of pectin enzymes produced from saccharomyces cerevisiae ATCC52712. Scientific Res. \& Essay. 2008; 3(9): 406-409.

27. Ofoefule SI, Osuji AC and O Okorie Effects of physical and chemical modifications on the disintegrant and dissolution properties of tacca involucrate starch. Bio-Research. 2004; 2(1):97-102.

28. Attama AA, Obi EN and IT Nzekwe The effects of Hypochlorite-oxidation on the physicochemical properties of starch obtained from tacca involucrate. Nigerian J .of Pharmaceutical Research. 2010;8(1):270-280. 